\title{
Safety, Precautions, and Modalities in Cancer Rehabilitation: an Updated Review
}

\author{
Jasmine Y. Zheng ${ }^{1}$ (D) Alyssa C. Mixon ${ }^{1} \cdot$ Mitra D. McLarney ${ }^{1}$ \\ Accepted: 31 May 2021 / Published online: 19 June 2021 \\ (C) The Author(s), under exclusive licence to Springer Science+Business Media, LLC, part of Springer Nature 2021
}

\begin{abstract}
Purpose of Review Providing rehabilitation to patients with cancer can be challenging due to the medical complexity associated with the illness and its treatments. This article provides the reader with a summary of frequently encountered medical conditions in the cancer population and associated safety considerations and precautions. An update on treatment modalities commonly used for symptom management is also presented.

Recent Findings Cancer and cancer treatments can cause changes in multiple organ systems. Special considerations and precautions are necessary to provide safe and effective rehabilitation. Physical modalities can be used as monotherapy or adjunct to treatment for common cancer-related side effects with recent studies noting benefit with a variety of modalities.

Summary Detailed assessment of the cancer patient is necessary before implementing a rehabilitation program. Understanding cancer and side effects of treatments, including newer options, are necessary to provide safe care.
\end{abstract}

Keywords Precautions $\cdot$ Safety $\cdot$ Modalities $\cdot$ Rehabilitation $\cdot$ Exercise $\cdot$ Therapy $\cdot$ Cancer

\section{Introduction}

Rehabilitation of patients with cancer poses unique challenges due to the medical complexity and the dynamic trajectory of their illnesses. Not only does the malignancy cause local and systemic changes to the body, but so can oncologic treatments, which include chemotherapy, radiation, surgery, stem cell therapy, and immunotherapy. These treatments can be given over long periods of time or in cycles. An understanding of how cancer and its associated treatments can affect the body and the body's response to rehabilitative measures, such as exercise prescriptions and therapy interventions, is essential in providing safe, timely,

This article is part of the Topical Collection on Cancer Rehabilitation

Jasmine Y. Zheng

Jasmine.zheng@pennmedicine.upenn.edu

Alyssa C. Mixon

Alyssa.mixon@pennmedicine.upenn.edu

Mitra D. McLarney

Mitra.mclarney@pennmedicine.upenn.edu

1 Department of Physical Medicine and Rehabilitation, University of Pennsylvania, 1800 Lombard St, 1st Floor, Philadelphia, PA 19146, USA and effective care $[1 \bullet \cdot]$. Unfortunately, a lack of awareness of rehabilitation services, its benefits, and relevant precautions may result in underutilization of rehabilitation $[2,3]$. This article will provide an up-to-date review of the current safety considerations and precautions when rehabilitating the cancer patient. Additionally, an updated review of treatment modalities and safety considerations will be discussed.

\section{Multi-organ Compromise}

Whether from the toxicities of chemotherapy and radiation to the adverse reactions seen with stem cell therapy and surgical procedures, precautions must be taken to mitigate the extent of comorbidities from cancer treatments. The gathering of a thorough history that includes details on cancer treatment, a comprehensive physical exam, and relevant imaging and laboratory studies prior to treatment can be extremely helpful in establishing a baseline and to help monitor for bodily changes through the cancer trajectory.

\section{Cardiorespiratory Considerations}

Cancer therapeutics can cause untoward cardiopulmonary effects. These effects can be immediate, such as after tumor 
debulking surgery, or can precipitate months to years later, such as seen after chemotherapy and radiation. Invasive surgical interventions such as pneumonectomies and lobectomies, which are commonly performed for lung cancer, may quickly precipitate decline in a patient's cardiorespiratory fitness and aerobic capacity [4]. Radiation side effects, on the other hand, can present acutely and subacutely as pericarditis, pericardial effusion, and pneumonitis $[5 \bullet, 6]$. Risk of pneumonitis increases with patient characteristics such as age over 65 , diagnosis of COPD, and a higher mean lung dose, or the lung volume that receives greater than 20 Gray of radiation $[5 \bullet, 7]$. Chronic radiation damage in the form of lung fibrosis is usually seen half a year to 2 years after radiation [5•]. Chronic cardiac toxicity typically occurs $10-15$ years after radiation and can present in a variety of ways, including as systolic and diastolic cardiomyopathy, arrythmias, premature coronary disease, and autonomic dysfunction [5•]. Risk of developing, and the severity of, cardiac diseases increases with higher radiation doses, larger organ volume irradiated, presence of adjuvant chemotherapy, and younger age at radiation treatment [8]. Radiation doses greater than 30 Gray to the heart valves increase the risk of significant heart valve disease [5•].

Both conventional chemotherapies and newer agents such as immunotherapies and targeted agents can induce cardiac toxicity. Anthracyclines such as doxorubicin and epirubicin, commonly used to treat breast cancer, lymphoma, and sarcoma, are known to cause heart failure and left ventricular dysfunction [6, 8]. Targeted therapies such as HER2 inhibitors including trastuzumab used in breast cancer, and VEGF inhibitors such as bevacizumab used in glioblastoma, can lead to cardiomyopathies. Bevacizumab is also known to cause arterial vascular disease, venous thromboembolisms, and hypertension [6]. More recently, treatment technology has evolved to include immunotherapies such as chimeric antigen receptor $\mathrm{T}$ cell therapy (CAR-T therapy) and immune checkpoint inhibitors. Both types of immunotherapy can cause arrythmias, cardiomyopathies, pulmonary hypertension, and arterial vascular disease [6].

In prescription of rehabilitation in those at risk of developing cardiopulmonary toxicity, or who already have impaired cardiac and respiratory function, understanding of their cancer treatment history and their baseline physiologic function through information obtained from electrocardiograms, echocardiograms, chest $\mathrm{x}$-rays, and pulmonary function tests is necessary to provide the most safe and effective recommendations [9]. This information can also be helpful in prescription of exercise type and intensity and in understanding the expected physiologic changes and response to rehabilitation over time. Studies examining exercise during and after cancer treatment have shown that improvements can be made in cardiopulmonary fitness [10]. Additionally, during therapy, vital sign and symptom monitoring (development of cough, dyspnea, chest pain, fatigue as examples) are recommended to avoid practices that can result in cardiopulmonary decompensation. Aerobic exercises may require supplemental oxygen to safely improve activity tolerance [4]. The authors recommend considering a consultation with a cardio-oncologist and/or pulmonologist before prescription of an exercise program if there are concerns regarding tolerance. Please see the "Exercise" section in this review for additional guidance on aerobic training.

\section{Neurologic Considerations}

Common neurologic complications in patients with cancer are often related to the treatment as opposed to the disease. Examples include chemotherapy-induced peripheral neuropathy (CIPN), immune cell effector-associated neurotoxicity syndrome (ICANS) associated with CAR-T therapy, and radiation-induced neurotoxicity. These conditions can cause neurologic changes that include sensory and motor deficits, gait and balance problems, and impaired cognition [11-13].

In those receiving chemotherapy, it is difficult to predict prior to treatment who will require more aggressive rehabilitation interventions, as there are currently no risk factors that will accurately predict how severe one's CIPN will be [13, 14]. Biomarker studies are currently underway to identify genetic predictors for neuropathy development [13]. Recognition of CIPN is important as approximately $17.2 \%$ of patients with CIPN is estimated to have fallen at the completion of chemotherapy [15]. Both pharmacologic and nonpharmacologic treatment options have been explored in prevention and treatment of CIPN. The 2020 ASCO Guideline Update on CIPN management in adult cancers discourages clinicians from using acetyl-L-carnitine to prevent CIPN [16•]. There is intermediate evidence to support use of duloxetine for those with CIPN [16•]. Examination of homebased exercise during chemotherapy showed that it can reduce CIPN symptoms; there were minimal adverse events and all were unrelated to the actual exercise treatment [17]. More recently, a randomized phase II pilot trial assessed changes in CIPN symptoms between those treated with transcutaneous electrical nerve stimulation (TENS) and Scrambler therapy [18]. There were twice as many patients in the Scrambler group who saw at least $50 \%$ pain reduction compared to the TENS group. There were no severe adverse events and there was minimal toxicity in both groups [18].

More recently, the development of CAR-T therapy transformed oncologic care for several cancers including lymphoma and leukemia; despite this, it also has toxicities that the practicing rehabilitation clinician must be aware of. Two of the most common side effects include cytokine release syndrome (CRS) and ICANS. CRS is an inflammatory response triggered by the CAR-T cells, activating the body's own immune system to release cytokines. ICANS may be related to 
endothelial activation and blood-brain barrier disruption [19]. It presents as toxic encephalopathy with symptoms including aphasia, word-finding difficulty, and confusion. It can lead to seizures, cerebral edema, weakness, and a decline in consciousness. These toxicities typically occur immediately after treatment and may require additional cognitive rehabilitation for orientation and improvements in thought processes [12].

Cognitive changes occur in an estimated $25-65 \%$ of patients who have undergone brain radiation and commonly include impairments in immediate and delayed memory, verbal fluency, attention, and executive function [5•]. Advances in radiation oncology have helped reduce neurotoxic complications related to whole-brain radiation therapy (WBRT). For example, brachytherapy for intracranial tumors provides more localization to target tissue, preventing damage to surrounding areas in contrast to WBRT. Additionally, it can limit radiation exposure from the patient to healthcare professionals and family members $[20,21]$. While there are potential benefits, it is important to note that brachytherapy does carry risk of infection; therefore, if a patient with brachytherapy has a sudden neurologic decline, clinicians must consider infection as a possible cause for the change [22]. Separately, advances in precision radiotherapy have led to the ability for hippocampal avoidance in WBRT, which has shown promising results in neurocognitive outcomes when compared to WBRT $[23,24]$.

When possible, an initial exam prior to starting treatment can be helpful to obtain baseline strength, sensation, balance, and cognitive information on the patient. At any point in treatment, recognition of other comorbidities that can affect the central and peripheral nervous system is important, as problems such as alcohol-induced neuropathy or vascular dementia can be confounding factors in the exam and can affect treatment recommendations. Ultimately, if the treatment is causing severe impairments, consider discussion with the treating oncologist. For example, if a patient's motor weakness began following chemotherapy and appear consistent with CIPN after other potential contributors to their symptoms have been excluded, it may be the best course of action to change the chemotherapy or adjust the dose [16•]. Specific physical, occupational, and speech therapy programs can focus on compensatory strategies for cognitive and other neurologic deficits, reduce fall risk, improve balance and coordination, improve strength, and make modifications to the living environment [25]. In those who demonstrate memory impairments due to radiation, prescription of a pharmacologic agent can be considered to support neurocognitive function and encourage improved participation in rehabilitation. Studies examining donepezil, an acetylcholinesterase inhibitor, have shown that it may improve attention, concentration, memory, and motor skills in previously brain irradiated patients [26]. Patients with brain metastases who were given memantine, an NMDA-receptor antagonist, showed longer time to cognitive decline and reduced delays in executive function compared to those who did not get the drug [26].

\section{Osseous Considerations}

Bone is a common site of cancer metastasis [27]. Rehabilitation specialists must be aware of locations of bony disease and general management approaches to ensure that prescription of rehabilitation does not cause fractures and further injury [28•]. Additionally, skeletal-related adverse events such as hypercalcemia and bone pain can impact participation in therapy, as well as concurrent osteoporosis, which can further increase risk of fracture [29].

Mirels' and Harrington's criteria are useful assessments for evaluating the risk of impending pathologic fractures to determine when prophylactic surgery is warranted. Mirels' score considers the location, size, lesion type, and degree of pain; a score greater than eight suggests need for surgery [30]. Harrington's criteria assess the presence of pain after radiation and the degree of destruction in the diaphysis, metaphysis, and subtrochanteric femoral region [31]. A separate tool called the Spinal Instability Neoplastic Score (SINS) helps identify patients with spinal tumors who may have spinal instability that requires surgical intervention. It is calculated using six radiographic and clinical factors with a score ranging from 0 to 18 [32]. SINS is deemed highly reliable, reproducible, and valid when it comes to evaluating spinal tumors [33]. The Fracture Risk Assessment Tool (FRAX) is another diagnostic method for determining fracture probability. It incorporates bone mineral density at the femoral head and clinical history to assess for 10-year osteoporotic fracture likelihood beyond $20 \%$ or hip fracture beyond 3\% [34].

Exercise has been shown to be generally safe and beneficial in patients with bone metastases. In a recent review of aerobic and resistance exercise in patients with bone metastases, interventions appeared to provide physical benefits with only a small number of adverse events, none of which was due to the exercise itself [35]. In a study that assessed an aerobic, resistance, and flexibility exercise program in patients with metastatic prostate cancer, there were improvements in physical function and strength without adverse events or increased pain [36]. In the study, loading of areas with bone metastases was avoided [36]. An ongoing randomized controlled pilot trial to assess safety and feasibility is underway to examine the effects of targeted exercise on tumor characteristics in breast cancer patients with bone metastases [37].

Recognizing a patient's risk profile with assessment tools, as well as the etiology of their condition (i.e., multiple myeloma versus primary or metastatic bone cancer), can help the rehabilitation clinician understand the risk of impending fracture and whether surgical evaluation is warranted. For example, the presence of bone metastases that infiltrate over $50 \%$ of cortical bone carries high morbidity and mortality [38]. 
Additionally, osteolytic tumors (such as in breast and lung cancer) have an increased chance of causing pathologic fractures than osteoblastic tumors (such as those seen in prostate cancer) [39]. Patients who undergo chemotherapy and radiation as well as hormonal therapy such as in the breast and gynecologic cancer population may require closer evaluation of bone mineral density. Postmenopausal women with breast cancer who are undergoing treatment with aromatase inhibitors are advised to obtain baseline dual energy x-ray absorptiometry (DEXA) scans every 1-2 years [40]. Those who are at increased potential for fractures due to osteoporosis and/or osteopenia may require the use of bisphosphonates.

Prior to starting a therapy program, the clinician must review and/or order the necessary imaging to ensure they are aware of locations of bony disease. Consultation with surgical specialties for recommendations on surgery or activity and weightbearing restrictions may be necessary. To protect and offer stability to affected areas, the clinician can consider the use of braces to the spine and to joints [41]. If physical activity poses a high risk for fracture, one can consider neuromuscular electrical stimulation (NMES) to promote muscle strength [42]. As the osseous fragility risk profile for a patient evolves, so do the rehabilitation needs of the patient and the recommendations offered by the physiatrist.

\section{Laboratory Abnormalities}

\section{Cytopenias}

Laboratory abnormalities are common findings in patients undergoing cancer treatments. Bone marrow suppression is a common phenomenon secondary to chemotherapy and radiation. Tumor involvement of the bone marrow can also result in pancytopenias. The resultant cell count changes can result in increased risk for infection and hemorrhage, while limiting wound healing. We recommend the practicing outpatient clinician routinely review the patient's complete blood count panel trends. Abnormal values may explain a new symptom that is limiting therapy participation, e.g., an acute anemia contributing to fatigue and decreased aerobic capacity. Additionally, abnormal values may necessitate therapy restrictions, such as asking a patient to avoid the public pool and instead perform home exercises due to a severe neutropenia. Prior to admission of a patient to acute rehabilitation, the inpatient rehabilitation team must discuss with the oncologic team if there will be an anticipated drop in cell counts. These patients may require prophylactic treatment such as granulocyte-macrophage colony-stimulating factor or additional blood product transfusions. They may also require a more individualized exercise regimen, with adjustments in intensity, weight, resistance, and duration.
Exercise-related bleeding complications are more likely to occur with lower platelets [43]. Fu et al. examined bleeding frequency in patients in acute inpatient rehabilitation with hematologic malignancies with severe thrombocytopenia (less than or equal to $20,000 / \mu 1$ ). The researchers found that bleeding frequency increased with lower platelet counts. Only 4\% of bleeding events were likely due to physical activity. It must be noted that the study was retrospective and only of an inpatient population, where patients are typically sicker and are more heavily supervised than those in an outpatient therapy or unsupervised exercise setting [43]. While physical activity is known to improve cardiopulmonary function, strength, and mobility, rehabilitation specialists must still weigh the risks and benefits associated with movement therapy, determine if any restrictions apply, to what extent, and for how long [43].

Clinicians must also be aware of any iatrogenic reasons for increased bleeding risk, for example, prescriptions of anticoagulants and antiangiogenic monoclonal antibodies such as bevacizumab and ramucirumab. Bevacizumab and ramucirumab do not induce thrombocytopenia, but rather increase risk of bleeding and thrombosis through inhibition of VEGF signaling, leading to disruption of tumor vasculature [44] (refer to Table 1 for clinical considerations of patients with thrombocytopenia undergoing rehabilitation).

Some patients with cancer may develop neutropenia and anemia. This can put them at increased risk for developing infections and hemodynamic instability [1••]. Recognizing a patient's baseline and lab trends can guide the management and ensure timely and appropriate interventions and workup are made to address these lab abnormalities before, during, and after therapy interventions. Depending on the levels, patients may have decreased endurance and aerobic capacity, limiting their participation. Neutropenia may also lead to neutropenic fevers, which is considered a medical emergency; thus, it is important to monitor lab values as well as vital signs including temperature closely [52] (refer to Table 1 for clinical considerations of patients with neutropenia and anemia undergoing rehabilitation).

These frequently encountered cytopenias can potentially increase bleeding and infection risks associated with procedures. In cancer patients with refractory or severe pain that are resistant to oral or parenteral agents, interventional pain procedures may be a helpful treatment option; yet, low cell counts may be a barrier. A recent retrospective analysis that examined 63 fluoroscopic spine injections in patients on cytotoxic chemotherapy for active cancer found that there were zero adverse events such as infection or bleeding when standard precautions were taken [53]. Unfortunately, there is no consensus nor clear guidelines from the Spine Intervention Society and other national organizations on safety and acceptable parameters for the performance of procedures in cancer patients on chemotherapies [53]. 
Table 1 Lab value considerations for rehabilitation in patients with cancer

\begin{tabular}{|c|c|}
\hline Lab type & Lab values and precautions \\
\hline Platelets & $\begin{array}{l}<150,000 \text { cells/uL (thrombocytopenia): monitor symptoms and tolerance } \\
>50,000 \text { cells/uL: monitor for symptoms (i.e., bleeding), progressive } \\
\text { aerobic and resistive exercise as tolerated } \\
>30,000 \text { cells/uL: moderate and active range of motion exercise, aquatic } \\
\text { therapy if candidate, monitor symptoms (i.e., bleeding) } \\
>20,000 \text { cells/uL: light exercise and ambulation, activities of daily living } \\
\text { without strenuous effort, monitor symptoms (i.e., bleeding), assess fall } \\
\text { risk, and implement fall precautions } \\
<20,000 \text { cells/uL: light activities of daily living and ambulation, monitor symptoms } \\
\text { (i.e., bleeding), fall precautions, be aware of transfusion requirements/plan } \\
{[1 \bullet, 43]}\end{array}$ \\
\hline $\begin{array}{l}\text { White blood cells } \\
\text { (total) }\end{array}$ & $\begin{array}{l}>11.010^{9} / \mathrm{L} \text { or }<4.010^{9} / \mathrm{L}: \text { monitor symptoms and vitals including temperature } \\
<1.510^{9} / \mathrm{L} \text { : monitor symptoms, neutropenic precautions } \\
{[1 \bullet \bullet, 45,46]}\end{array}$ \\
\hline $\begin{array}{l}\text { Red blood cells } \\
\text { (hemoglobin) }\end{array}$ & $\begin{array}{l}<11 \mathrm{~g} / \mathrm{dL} \text { (anemia): obtain baseline vital signs, monitor signs and symptoms } \\
\quad \text { (i.e., tachycardia and orthostatic hypotension) } \\
<8 \mathrm{~g} / \mathrm{dL} \text { (severe anemia): monitor vital signs and symptoms, transfusion may or } \\
\text { may not be indicated, rehabilitation may be limited and need to be performed } \\
\text { in short intervals, assess for tolerance and educate on energy conservation. } \\
{[1 \bullet \bullet, 47]}\end{array}$ \\
\hline Sodium & $\begin{array}{l}\text { Normal values of sodium are } 135-145 \mathrm{mmol} / \mathrm{L} \text {. } \\
\text { Hyponatremia }(<135 \mathrm{mmol} / \mathrm{L}) \text { is most commonly associated with lung cancer and } \\
\text { may be considered an adverse prognostic indicator. It is commonly due to SIADH } \\
\text { and volume depletion. Acute presentations can lead to cerebral edema, causing } \\
\text { impaired cognition and level of consciousness, seizures, elevated intracranial } \\
\text { pressure, and in some cases death. Monitor labs and consider fluid restriction versus } \\
\text { diuretics or vasopressin receptor antagonists. } \\
{[48-50]}\end{array}$ \\
\hline Potassium & $\begin{array}{l}\text { Normal values of potassium are between } 3.5 \text { and } 5.0 \mathrm{mmol} / \mathrm{L} \text {. } \\
\text { Hyperkalemia ( }>5.5 \mathrm{mmol} / \mathrm{L} \text { ) can increase risk of cardiac arrhythmias and elevated } \\
\text { values are often seen in tumor lysis syndrome. Monitor labs, check EKG, and treat } \\
\text { accordingly (such as calcium gluconate to stabilize cardiac excitation, beta agonist, } \\
\text { insulin and glucose, kayexalate, dialysis). } \\
\text { [45] }\end{array}$ \\
\hline Calcium & $\begin{array}{l}\text { Normal values of calcium range from } 8.8 \text { to } 10.4 \mathrm{mg} / \mathrm{dL} \text {. } \\
\text { Hypocalcemia }(<8.8 \mathrm{mg} / \mathrm{dL}) \text { can lead to cardiac arrhythmias and is often seen in tumor } \\
\text { lysis syndrome. In contrast, hypercalcemia }(>10.4 \mathrm{mg} / \mathrm{dL}) \text { is considered a negative } \\
\text { prognostic factor in multiple myeloma. Hypercalcemia can also be seen in } \\
\text { widespread bony metastases. } \\
\text { It is associated with kidney stones, bone and abdominal pain, mood disorders, and } \\
\text { weakness. } \\
\text { Both hypocalcemia and hypercalcemia require close lab monitoring and electrolyte } \\
\text { optimization. } \\
{[45,51]}\end{array}$ \\
\hline
\end{tabular}

\section{Electrolyte Abnormalities}

Electrolyte abnormalities are also commonly seen in the cancer population. For example, widespread bony metastases can lead to hypercalcemia, which often presents as nausea, abdominal pain, and occasionally muscle abnormalities [54]. Of the electrolytes, sodium and calcium can have prognostic implications in certain cancers [48-51]. Routine monitoring and supplementing electrolytes appropriately in the rehabilitation setting can help avoid preventable events, such as cardiac arrythmias and cognitive changes. Table 1 reviews in detail signs and symptoms as well as management of these disorders.

Systemic corticosteroids are widely used during cancer treatment and have several beneficial properties including being anti-inflammatory, anti-emetic, anti-allergic, and anti-cancer. It can also lead to hypokalemia, skeletal dysfunction, mood disorders, and adrenal 
insufficiency. Prior to starting a rehabilitation program, the dosage and duration for corticosteroids should be reviewed with the goal of using the lowest dose and for the shortest period [55].

\section{Additional Considerations}

\section{Lymphedema}

Lymphedema, the abnormal accumulation of protein-rich fluid in a part of the body, is a common condition in cancer patients secondary to lymphatic system disruption by surgery, radiation, or cancer itself [56]. Once it occurs, lymphedema requires lifelong treatment [56]. Thus, it is imperative that clinicians understand necessary precautions to take when prescribing rehabilitation and educate patients as well.

Exercise in breast cancer-associated lymphedema has been extensively studied, including aerobic exercise in the form of cycling and elliptical use, water therapies, and walking, none of which has been found to increase swelling [57-59]. Additionally, resistance exercises have not been found to increase lymphedema in breast cancer patients [60]. More recently, in a randomized control trial of 158 women with breast cancer after axillary lymph node dissection, there was no significant arm volume difference at 12 months between the intervention group that underwent progressive resistance exercise and the usual care group. There were also no adverse events that resulted in drop out from the study [61]. In addition, two large retrospective cohort studies found no evidence that air travel, intravenous access or injections, and blood pressure measurements result in lymphedema development $[62,63]$.

The gold standard of lymphedema treatment is complete decongestive therapy. Clinicians must also be aware of pneumatic compression devices, which are sometimes encountered as an option when treating lymphedema. Use of pneumatic compression devices is controversial, due to concerns of improper use resulting in new or worsening swelling, or lack of substantial benefit [64]. A randomized single-blind controlled study of 46 breast cancer patients with lymphedema found that manual lymphatic drainage and pneumatic compression use were equally useful in improving arm measurements and discomfort [65]. Use of a pneumatic compression device in 43 head and neck cancer survivors with lymphedema demonstrated no adverse effects [66]. It is the authors' opinion that some newer generation pneumatic compression devices, used cautiously and with oversight in some patients, can be an adjunct in treatment but do not replace complete decongestive therapy or need for compression garments. When considering prescribing a pneumatic compression device, an understanding of how the device works is crucial. Benefits must be weighed against the cost of the device and whether patients will be compliant in sitting through the full cycle of treatment. To ensure safety, patients must be educated to look for abnormal symptoms such as increased pain, swelling, and skin irritation. Additionally, patients must be able to independently monitor their symptoms and be able to don and doff the device independently or have a caregiver who can assist. Contraindications to use of pneumatic compression devices include decompensated congestive heart failure, pulmonary edema, ischemic vascular disease, severe peripheral neuropathy, cellulitis, pulmonary embolism, and known or suspected deep vein thrombosis [67].

\section{Nutrition}

Cancer patients are at high risk for malnutrition, which can further exacerbate their immunodeficiency, adversely affect well-being, and lead to poor outcomes. This requires proactive evaluations and monitoring of nutrition status and metabolic needs, from checking albumin and pre-albumin to performing swallow studies and consulting nutrition experts. Due to their vulnerable state, the cancer population has a higher likelihood of developing sarcopenia and/or cachexia as well as cancerrelated fatigue. In a study by Mayanagi et al., preoperative sarcopenia in esophageal cancer patients was more likely to develop postoperative dysphagia, suggesting the importance of pre-surgical nutritional supplementation [68]. While cancer-related fatigue is known to improve with supervised moderate-hard resistance training with or without moderatevigorous aerobic exercise, there is evidence to suggest that nutritional interventions may also improve quality of life [69].

With increased exercise regimens comes the need for increased caloric intake to support this energy expenditure. Additional benefits can be seen with improved quality of life and decreased symptoms of nausea and vomiting [70]. Throughout the rehabilitation continuum, clinicians should remember to optimize patients' diets through oral, parenteral, or enteral feedings in addition to fortifying supplements [71]. In the authors' clinical experience, patients receiving total parenteral nutrition (TPN) do not appear to progress functionally as well in acute rehabilitation as compared to other patients not on TPN. However, more thorough investigative studies need to be conducted to determine the clinical significance of this observation.

\section{COVID-19 Pandemic}

The COVID-19 pandemic has brought unique challenges for rehabilitation of the cancer patient. Cancer patients are at increased risk of SARS-COV-2 infection and at increased risk of developing severe disease compared to their non-cancer counterparts $[72,73]$. In an effort to reduce risk of infection, noncontact methods have been emphasized when possible [74]. This has forced the rehabilitation and oncologic 
community to evaluate the necessity and safety of rehabilitation therapy interventions in the cancer population. Community exercise programs, outpatient physical therapy sessions were temporary eliminated, or continue to pose a risk for patients in their immunocompromised state. To thwart the barrier posed by the pandemic, many healthcare organizations have proposed or implemented rehabilitation services virtually.

Sell et al. developed a prehabilitation program for patients with pancreatic ductal adenocarcinoma before surgical resection that was a home-based multimodal intervention, including a standardized fitness program. Like in person exercise, warning to the patient on specific risks of exercise (such as on bony metastases) still applies [75]. Morrison et al. reviewed the feasibility and impact of exercise telehealth interventions in cancer patients and found that the majority used a webbased platform for the delivery of exercises [76 ${ }^{\circ}$. Others used wearable devices and SMS messaging [76 ${ }^{\bullet}$. There were generally improvements in physical outcomes and some in psychosocial outcomes and the interventions were overall safe [76•]. In two studies that assessed the use of telemedicine for outpatient cancer rehabilitation visits, virtual delivery of care was useful for education and counseling and could be an acceptable and safe alternative to in-person visits $[77,78]$. Those patients with new problems or a neuromusculoskeletal issue generally still required in-person visits $[77,78]$. The pandemic has sped the development of virtual platforms for telerehabilitation, and the latter will likely stay and evolve long after the pandemic has resolved.

\section{Exercise}

Exercise has been shown to be safe and effective for cancer patients at all stages of treatment $[1 \bullet \bullet]$. Cancer patients who participate in exercise have been found to have improved quality of life and decreased anxiety, depression, fatigue, and sleep disorders [79-81]. Furthermore, when exercise is initiated prior to or concurrent with cancer treatment, there has been a noted overall improvement in tolerance to cancer treatment, functional outcomes, cardiorespiratory function, and decreased risk of cancer-related mortality and cancer recurrence $[82,83]$. Despite these known benefits, participation in exercise programs remains limited with previous studies finding less than half of cancer patients participate in regular physical activity [84०0]. Some of the barriers to participation in exercise programs for these patients include the following: patient health concerns, limited time and access to resources, and referring physicians' lack of awareness and familiarity with prescribing exercise programs for these patients [84••, 85]. In 2019, Schmitz et al. suggested tools that could be used by providers to increase referral for exercise programs in cancer patients $[84 \cdot \bullet]$.
It is recommended that cancer patients participate in a combination of aerobic training, resistance training, and lowimpact exercises such as tai chi and yoga. Previous studies suggest that aerobic exercise should be performed at a moderate to vigorous level of intensity for greatest benefits [83••]. The American College of Sports Medicine Roundtable Report from 2018 currently recommends cancer patients participate in a minimum of $150 \mathrm{~min}$ of moderate or $75 \mathrm{~min}$ of vigorous aerobic exercise per week and 2 days of resistance-based exercise training per week [81]. When prescribing an exercise program, providers may suggest modifications and limitations based on the patient's cancer diagnosis, anti-neoplastic treatments, or side effects from these treatments such as infection, thromboembolic disease, and hemorrhage.

\section{Therapeutic Modalities}

The use of manual therapies and physical modalities have benefits when it comes to treating common cancer symptoms such as fatigue, pain, chemotherapy-induced nausea vomiting, polyneuropathy, and lymphedema [1••, 86-97]. Modalities such as heat, ultrasound, cryotherapy, and manual therapy have been commonly used as adjuncts for the treatment of cancer-related pain, management of tissue inflammation, and promotion of muscle relaxation $[1 \bullet \cdot]$. There has been concern that modalities such as ultrasound and electrical stimulation can cause tumor growth and propagation. In a study that showed tumor growth in mice treated with continuous and pulse ultrasound, the total ultrasound energy was higher than that which would be used in a therapy clinic [98]. Separately, several electrical stimulation studies have shown that the modality may actually limit cancer growth [99]. Despite this, the authors recommend avoiding placement of ultrasound and electrical stimulation directly over a tumor site out of an abundance of caution. Recently, the International Society for Medical Shockwave Treatment issued clinical recommendations on use of extracorporeal shock wave therapy based on current literature [96]. While use of shock waves is contraindicated when the treatment areas include the malignant tumor, cancer itself is not a contraindication [96].

In recent years, the addition of medical marijuana, acupuncture, and low-impact exercise such as tai chi and yoga has shown benefit in the appropriate cancer patient $[80,88,90$, 93, 97, 100-107]. Medical marijuana has gained popularity for its ability to treat pain, refractory nausea, and vomiting and improve appetite; however, caution should be taken with use of this agent in patients with previous psychiatric or cardiac conditions [101, 102].

Acupressure and acupuncture techniques have been used for centuries in traditional Eastern medicine practices to treat a variety of medical conditions and symptoms [106]. These practices have gained popularity in Western medicine as monotherapy or in conjunction with other treatments to 
Table 2 Commonly used treatment modalities in cancer rehabilitation and their associated indications, precautions, and contraindications

\begin{tabular}{|c|c|c|c|}
\hline Treatment & Indications & Precautions & Contraindications \\
\hline $\begin{array}{l}\text { Acupressure } \\
{[86,93]}\end{array}$ & $\begin{array}{l}\text { - Fatigue } \\
\text { - Chemotherapy-induced } \\
\text { nausea/vomiting }\end{array}$ & - Skin fragility & - Open wounds \\
\hline $\begin{array}{l}\text { Acupuncture } \\
{[87,88,93,103-105,107,110]}\end{array}$ & $\begin{array}{l}\text { - Chemotherapy-induced peripheral } \\
\text { neuropathy } \\
\text { - Lymphedema } \\
\text { - Fatigue } \\
\text { - Pain relief } \\
\text { - Anxiety/depression } \\
\text { - Appetite stimulant } \\
\text { - Xerostomia }\end{array}$ & $\begin{array}{l}\text { - Anticoagulation } \\
\text { - Pregnancy } \\
\text { - Skin fragility }\end{array}$ & $\begin{array}{l}\text { - Thrombocytopenia } \\
\text { - Leukopenia } \\
\text { - Altered mental status } \\
\text { - Cardiac Arrhythmias } \\
\text { - Local malignancy } \\
\text { - Active infection } \\
\text { - Active psychosis/delusions } \\
\text { - Burns }\end{array}$ \\
\hline $\begin{array}{l}\text { Cryotherapy } \\
{[1 \bullet, 111,112]}\end{array}$ & $\begin{array}{l}\text { - Oral mucositis } \\
\text { - Chemotherapy-induced peripheral } \\
\text { neuropathy } \\
\text { - Pain relief } \\
\text { - Acute management of inflammation } \\
\text { - Hair loss management }\end{array}$ & $\begin{array}{l}\text { - Sensory deficits } \\
\text { - Open wounds }\end{array}$ & $\begin{array}{l}\text { - Peripheral vascular disease } \\
\text { - Tissue ischemia }\end{array}$ \\
\hline $\begin{array}{l}\text { Electro-acupuncture }[88 \cdot, 92,93 \text {, } \\
\text { 107] }\end{array}$ & $\begin{array}{l}\text { - Pain relief } \\
\text { - Chemotherapy-induced } \\
\text { nausea/vomiting }\end{array}$ & $\begin{array}{l}\text { - Anticoagulation } \\
\text {-Pregnancy } \\
\text { - Skin fragility }\end{array}$ & $\begin{array}{l}\text { - AICD/pacemaker } \\
\text { - Placement over heart/brain }\end{array}$ \\
\hline $\begin{array}{l}\text { Extracorporeal shock wave therapy } \\
{[95,96,113,114]}\end{array}$ & $\begin{array}{l}\text {-Musculoskeletal pain } \\
\text { - Lymphedema } \\
\text {-Polyneuropathy }\end{array}$ & - Skin fragility & $\begin{array}{l}\text { - Malignant tumor } \\
\text { - Multiple myeloma } \\
\text { - Acute leukemia } \\
\text { - Severe coagulopathy } \\
\text { - Wound infections } \\
\text { - Growth plate }\end{array}$ \\
\hline $\begin{array}{l}\text { Manual therapy } \\
{[1 \bullet \bullet, 91,115]}\end{array}$ & $\begin{array}{l}\text { - Tissue and muscle relaxation } \\
\text { - Joint mobility } \\
\text { - Lymphatic massage } \\
\text { - Pain } \\
\text { - Dysphagia }\end{array}$ & $\begin{array}{l}\text { - Sensory deficits } \\
\text { - Tissue ischemia } \\
\text { - Open wounds }\end{array}$ & $\begin{array}{l}\text { - Malignant tumor } \\
\text { - Bone fragility } \\
\text { - Acute radiation dermatitis }\end{array}$ \\
\hline $\begin{array}{l}\text { Medical marijuana } \\
{[94,100-102,116]}\end{array}$ & $\begin{array}{l}\text { - Pain relief } \\
\text { - Sleeping disorders } \\
\text { - Anxiety } \\
\text { - Nausea/vomiting }\end{array}$ & $\begin{array}{l}\text { - Mood or anxiety disorder } \\
\text { - Tobacco use }\end{array}$ & $\begin{array}{l}\text { - History of psychiatric disorders } \\
\text { - Unstable cardiac conditions }\end{array}$ \\
\hline $\begin{array}{l}\text { Mindfulness } \\
{[80,117]}\end{array}$ & $\begin{array}{l}\text { - Fatigue } \\
\text { - Stress } \\
\text { - Insomnia } \\
\text { - Anxiety/depression } \\
\text { - Cancer-related pain }\end{array}$ & $\begin{array}{l}\text { - History of psychiatric } \\
\text { disorders } \\
\text { - Post-traumatic stress } \\
\text { - Addiction }\end{array}$ & \\
\hline Photobio-modulation & - Oral mucositis & - Bone growth plate & - Acute radiation dermatitis \\
\hline$[1 \bullet \bullet, 113,118,119]$ & $\begin{array}{l}\text { - Lymphedema } \\
\text { - Scarred, fibrotic tissue }\end{array}$ & - Open wounds & - Malignant tumor \\
\hline $\begin{array}{l}\text { Tai chi } \\
{[79,80,88,97]}\end{array}$ & $\begin{array}{l}\text { - Pain } \\
\text { - Fatigue }\end{array}$ & $\begin{array}{l}\text { - Heart disease } \\
\text { - Bone metastases }\end{array}$ & - Fractures \\
\hline $\begin{array}{l}\text { Transcutaneous electrical nerve } \\
\text { stimulation } \\
{[1 \bullet \cdot, 120]}\end{array}$ & $\begin{array}{l}\text { - Desensitization } \\
\text { - Pain } \\
\text { - Nausea } \\
\text { - Poor appetite }\end{array}$ & - Impaired sensation & $\begin{array}{l}\text { - Malignant tumor } \\
\text { - AICD/pacemaker } \\
\text { - Open wounds }\end{array}$ \\
\hline $\begin{array}{l}\text { Ultrasound } \\
{[1 \bullet \bullet, 113]}\end{array}$ & - Tissue and muscle relaxation & $\begin{array}{l}\text { - Bone growth plate } \\
\text { - Infection } \\
\text { - Impaired sensation } \\
\text { - Open wounds }\end{array}$ & $\begin{array}{l}\text { - Areas of active or previously treated } \\
\text { cancer }\end{array}$ \\
\hline $\begin{array}{l}\text { Yoga } \\
{[79,80,88,97]}\end{array}$ & $\begin{array}{l}\text { - Pain } \\
\text { - Chemotherapy-induced peripheral } \\
\text { neuropathy } \\
\text { - Fatigue } \\
\text { - Lymphedema } \\
\text { - Insomnia } \\
\text { - Nausea/vomiting }\end{array}$ & $\begin{array}{l}\text { - Heart disease } \\
\text { - Pleural effusions } \\
\text { - Ascites } \\
\text { - Bone metastases }\end{array}$ & - Fractures \\
\hline
\end{tabular}


effectively treat fatigue, nausea/vomiting, pain, mood disturbances, and lymphedema with minimal risk in cancer patients $[87,93,103,104]$. Yoga and tai chi exercise programs provide a method to treat cancer-related symptoms while promoting mobility and bone health.

Current research looking at the implementation of these practices at different stages during a cancer patient treatment course, from acute hospitalization to outpatient care, have found benefit in treating pain, fatigue, and anxiety $[108,109]$.

Medical providers should be aware of the physical modalities that are available to treat cancer symptoms and the population that may benefit. Table 2 below lists common physical modalities and therapies used in cancer patients as well as precautions/contraindications to their prescription.

\section{Conclusions}

Various considerations need to be considered when rehabilitating the cancer population. Surgery, chemotherapy, radiation, and newer therapies, such as immunotherapy, can cause acute and chronic changes that impact patient's ability to tolerate and perform rehabilitative exercises. Exercise and rehabilitative treatment modalities can be safe if implemented appropriately. Certain therapies may be contraindicated or pose risk. A thorough history, exam, and necessary laboratory testing and imaging should be completed prior to rehabilitation. As the cancer trajectory changes from diagnosis to survivorship, so may precautions, and clinicians need to be proactive in making appropriate adjustments to rehabilitation approaches as necessary.

\section{Declarations}

Conflict of Interest None of the authors has any potential conflicts of interest to disclose.

Human and Animal Rights and Informed Consent This article does not contain any studies with human or animal subjects performed by any of the authors.

\section{References}

Papers of particular interest, published recently, have been highlighted as:

- Of importance

•- Of major importance

1.• Maltser S, Cristian A, Silver JK, Morris GS, Stout NL. A focused review of safety considerations in cancer rehabilitation. PM R. 2017;9:S415-28. Review article on special precautions to consider in cancer rehabilitation, which helped lay the groundwork for the current updated review.

2. Silver JK, Raj VS, Fu JB, Wisotzky EM, Smith SR, Kirch RA. Cancer rehabilitation and palliative care: critical components in the delivery of high-quality oncology services. Support Care Cancer. 2015;23:3633-43.

3. Yang EJ, Chung SH, Jeon J, Seo KS, Shin H, Hwang JH, et al. Current practice and barriers in cancer rehabilitation: perspectives of Korean physiatrists. Cancer Res Treat. 2015;47:370.

4. Cifu DX (2020) Braddom's physical medicine and rehabilitation E-book. Elsevier Health Sciences,

5. De Ruysscher D, Niedermann G, Burnet NG, Siva S, Lee AWM, Hegi-Johnson F (2019) Radiotherapy toxicity 5:1-20. Comprehensive update on the various ways radiation can affect the organ systems.

6. Herrmann J (2020) Adverse cardiac effects of cancer therapies: cardiotoxicity and arrhythmia 17:474-502

7. Giuranno L, Ient J, De Ruysscher D, Vooijs MA (2019) Radiation-induced lung injury (RILI) 9:877

8. Lenneman CG, Sawyer DB. Cardio-oncology: an update on cardiotoxicity of cancer-related treatment. Circ Res. 2016;118: 1008-20.

9. Peel AB, Thomas SM, Dittus K, Lee, Jones W, Lakoski SG Cardiorespiratory fitness in breast cancer patients: a call for normative values

10. Squires RW, Shultz AM, Herrmann J. Exercise training and cardiovascular health in cancer patients. Curr Oncol Rep. 2018;20:120.

11. Delanian S, Lefaix J, Pradat P (2012) Radiation-induced neuropathy in cancer survivors 105:273-282

12. Neelapu SS. Managing the toxicities of CAR T-cell therapy. Hematol Oncol. 2019;37:48-52. https://doi.org/10.1002/hon. 2595.

13. Chan Y, Jheng Y, Wang Y. Chemotherapy-induced peripheral neurotoxicity as a risk factor for poor sleep quality in breast cancer survivors treated with docetaxel. Asia Pac J Oncol Nurs. 2021;8: 68.

14. Molassiotis A, Cheng HL, Leung KT, Li YC, Wong KH, Au JSK, et al. Risk factors for chemotherapy-induced peripheral neuropathy in patients receiving taxane-and platinum-based chemotherapy. Brain Behav. 2019;9:e01312.

15. Argyriou AA, Bruna J, Anastopoulou GG, Velasco R, Litsardopoulos P, Kalofonos HP. Assessing risk factors of falls in cancer patients with chemotherapy-induced peripheral neurotoxicity. Support Care Cancer. 2020;28:1991-5.

16. Loprinzi CL, Lacchetti C, Bleeker J, Cavaletti G, Chauhan C, Hertz DL, et al. Prevention and management of chemotherapyinduced peripheral neuropathy in survivors of adult cancers: ASCO guideline update. J Clin Oncol. 2020;38:3325-48. Updated evidence-based guidelines on management of chemotherapy-induced peripheral neuropathy.

17. Kleckner IR, Kamen C, Gewandter JS, Mohile NA, Heckler CE, Culakova E, et al. Effects of exercise during chemotherapy on chemotherapy-induced peripheral neuropathy: a multicenter, randomized controlled trial. Support Care Cancer. 2018;26:1019-28.

18. Loprinzi C, Le-Rademacher JG, Majithia N, McMurray RP, O'Neill CR, Bendel MA, et al. Scrambler therapy for chemotherapy neuropathy: a randomized phase II pilot trial. Support Care Cancer. 2020;28:1183-97.

19. Gust J, Hay KA, Hanafi L, Li D, Myerson D, Gonzalez-Cuyar LF, et al. Endothelial activation and blood-brain barrier disruption in neurotoxicity after adoptive immunotherapy with CD19 CAR-T cells. Cancer Discov. 2017;7:1404-19.

20. Yondorf MZ, Schwartz TH, Boockvar JA, Pannullo S, Stieg P, Sabbas A, Pavese A, Trichter S, Nedialkova L, Parashar B, Nori D, Chao KSC, Wernicke AG Radiation exposure and safety 
precautions following 131 Cs brachytherapy in patients with brain tumors

21. Chitti B, Goyal S, Sherman JH, Caputy A, Sarfaraz M, Cifter G, et al. The role of brachytherapy in the management of brain metastases: a systematic review. J Contemp Brachyther. 2020;12:67.

22. Koch MJ, Agarwalla PK, Royce TJ, Shih HA, Oh K, Niemierko A, et al. Brachytherapy as an adjuvant for recurrent atypical and malignant meningiomas. Neurosurgery. 2019;85:E910-6.

23. Lee G, Besse L, Lamba N, Hancox C, Usta I, Hacker F, et al. Feasibility of hippocampal avoidance whole brain radiation in patients with hippocampal involvement: data from a prospective study. Med Dosim. 2021;46:21-8.

24. Zhao R, Kong W, Shang J, Zhe H, Wang Y. Hippocampal-sparing whole-brain radiotherapy for lung cancer. Clin Lung Cancer. 2017;18:127-31.

25. McCrary JM, Goldstein D, Sandler CX, Barry BK, Marthick M, Timmins HC, et al. Exercise-based rehabilitation for cancer survivors with chemotherapy-induced peripheral neuropathy. Support Care Cancer. 2019;27:3849-57.

26. van Lonkhuizen PJ, Klaver KM, Wefel JS, Sitskoorn MM, Schagen SB, Gehring K. Interventions for cognitive problems in adults with brain cancer: a narrative review. Eur J Cancer Care. 2019;28:e13088.

27. Chin H, Kim J. Bone metastasis: concise overview. Fed Pract. 2015;32:24.

28. Guo Y, Ngo-Huang A, Fu JB. Perspectives on spinal precautions in patients who have cancer and spinal metastasis. Phys Ther. 2020;100:554-63. https://doi.org/10.1093/ptj/pzz178. Updated review of spinal metastasis, associated risks/complications, and rehabilitation interventions.

29. Yang M, Liu C, Yu X. Skeletal-related adverse events during bone metastasis of breast cancer: Current status. Discov Med. 2019;27: 211-20.

30. Ramsey DC, Lam PW, Hayden J, Doung Y, Gundle KR. Mirels scores in patients undergoing prophylactic stabilization for femoral metastatic bone disease in the Veterans Administration Healthcare System. J Am Acad Orthop Surg Glob Res Rev. 2020;4:e2000141. https://doi.org/10.5435/JAAOSGlobal-D-2000141.

31. Piccioli A, Spinelli MS, Maccauro G. Impending fracture: a difficult diagnosis. Injury. 2014;45:S138-41. https://doi.org/10.1016/ j.injury.2014.10.038.

32. Fisher CG, Schouten R, Versteeg AL, Boriani S, Varga PP, Rhines LD, et al. Reliability of the Spinal Instability Neoplastic Score (SINS) among radiation oncologists: an assessment of instability secondary to spinal metastases. Radiat Oncol. 2014;9:69. https://doi.org/10.1186/1748-717X-9-69.

33. Fourney DR, Frangou EM, Ryken TC, Di Paola CP, Shaffrey CI, Berven SH, et al. Spinal Instability Neoplastic Score: an analysis of reliability and validity from the Spine Oncology Study Group. J Clin Oncol. 2011;29:3072-7. https://doi.org/10.1200/JCO.2010. 34.3897.

34. Leslie WD, Majumdar SR, Lix LM, Johansson H, Oden A, Mccloskey E, et al. High fracture probability with FRAX® usually indicates densitometric osteoporosis: implications for clinical practice. Osteoporos Int. 2012;23:391-7. https://doi.org/10.1007/ s00198-011-1592-3.

35. Sheill G, Guinan EM, Peat N, Hussey J. Considerations for exercise prescription in patients with bone metastases: a comprehensive narrative review. PM R. 2018;10:843-64.

36. Galvao DA, Taaffe DR, Spry N, Cormie P, Joseph D, Chambers SK, et al. Exercise preserves physical function in prostate cancer patients with bone metastases. Med Sci Sports Exerc. 2018;50: 393-9.

37. Hart NH, Galvão DA, Saunders C, Taaffe DR, Feeney KT, Spry NA, et al. Mechanical suppression of osteolytic bone metastases in advanced breast cancer patients: a randomised controlled study protocol evaluating safety, feasibility and preliminary efficacy of exercise as a targeted medicine. Trials. 2018;19:1-15.

38. Coleman R, Body JJ, Aapro M, Hadji P, Herrstedt J. Bone health in cancer patients: ESMO clinical practice guidelines. Ann Oncol. 2014;25(Suppl 3):iii124-37. https://doi.org/10.1093/annonc/ mdu103.

39. Ashford R, Lor Randall R (2016) Bone metastases: epidemiology and societal effect. In: Anonymous, pp 3-11.

40. Stratton J, Hu X, Soulos PR, Davidoff AJ, Pusztai L, Gross CP, et al. Bone density screening in postmenopausal women with early-stage breast cancer treated with aromatase inhibitors. J Oncol Pract. 2017;13:e505-15.

41. Keilani M, Kainberger F, Pataraia A, Hasenöhrl T, Wagner B, Palma S, et al. Typical aspects in the rehabilitation of cancer patients suffering from metastatic bone disease or multiple myeloma. Wien Klin Wochenschr. 2019;131:567-75.

42. Crevenna R, Kainberger F, Wiltschke C, Marosi C, Wolzt M, Cenik F, et al. Cancer rehabilitation: current trends and practices within an Austrian University Hospital Center. Disabil Rehabil. 2020;42:2-7.

43. Fu J, Tennison J, Rutzen-Lopez I, Silver J, Morishita S, Dibaj S, et al. Bleeding frequency and characteristics among hematologic malignancy inpatient rehabilitation patients with severe thrombocytopenia. Support Care Cancer. 2018;26:3135-41. https://doi. org/10.1007/s00520-018-4160-y.

44. Xiao B, Wang W, Zhang D. Risk of bleeding associated with antiangiogenic monoclonal antibodies bevacizumab and ramucirumab: a meta-analysis of 85 randomized controlled trials. Onco Targets Ther. 2018;11:5059.

45. Rahmani B, Patel S, Seyam O, Gandhi J, Reid I, Smith NN, et al. Current understanding of tumor lysis syndrome. Hematol Oncol. 2019;37:537-47. https://doi.org/10.1002/hon.2668.

46. Granger JM, Kontoyiannis DP. Etiology and outcome of extreme leukocytosis in 758 nonhematologic cancer patients. Cancer. 2009;115:3919-23. https://doi.org/10.1002/cncr.24480.

47. Groopman JE, Itri LM Chemotherapy-induced anemia in adults: incidence and treatment assessing chemotherapy-induced anemia and its impact

48. Castillo JJ, Vincent M, Justice E. Diagnosis and management of hyponatremia in cancer patients. Oncologist. 2012;17:756-65. https://doi.org/10.1634/theoncologist.2011-0400.

49. Hannon MJ, Thompson CJ. Neurosurgical hyponatremia. J Clin Med. 2014;3:1084-104. https://doi.org/10.3390/jcm3041084.

50. Kitchlu A, Rosner M. Hyponatremia in patients with cancer. Curr Opin Nephrol Hypertens. 2019;28:433-40. https://doi.org/10. 1097/MNH.0000000000000525.

51. Zagouri F, Kastritis E, Zomas A, Terpos E, Katodritou EE, Symeonidis A, et al. Hypercalcemia remains an adverse prognostic factor for newly diagnosed multiple myeloma patients in the era of novel antimyeloma therapies. Eur J Haematol. 2017;99: 409-14. https://doi.org/10.1111/ejh.12923.

52. Kuderer NM, Dale DC, Crawford J, Cosler LE, Lyman GH. Mortality, morbidity, and cost associated with febrile neutropenia in adult cancer patients. Cancer. 2006;106:2258-66. https://doi. org/10.1002/cncr.21847.

53. Joyce E, Bakshi R, Fediw M, Smith SR (2021) Safety of fluoroscopically guided pain procedures in patients receiving cytotoxic chemotherapy: a retrospective analysis $1-6$

54. Stubblefield MD, O'Dell MW (2009) Cancer rehabilitation: principles and practice. Demos Medical Publishing

55. Aldea M, Orillard E, Mansi L, Marabelle A, Scotte F, Lambotte O, et al. How to manage patients with corticosteroids in oncology in the era of immunotherapy? Eur J Cancer. 2020;141:239-51. https://doi.org/10.1016/j.ejca.2020.09.032. 
56. Grada AA, Phillips TJ. Lymphedema: pathophysiology and clinical manifestations. J Am Acad Dermatol. 2017;77:1009-20.

57. Courneya KS, Segal RJ, Mackey JR, Gelmon K, Reid RD, Friedenreich CM, et al. Effects of aerobic and resistance exercise in breast cancer patients receiving adjuvant chemotherapy: a multicenter randomized controlled trial. J Clin Oncol. 2007;25:4396404.

58. Hayes S, Reul-Hirche H, Turner J. Exercise and secondary lymphedema: safety, potential benefits, and research issues. Med Sci Sports Exerc. 2009;41:483-9.

59. Di Blasio A, Morano T, Bucci I, Di Santo S, D’Arielli A, Castro CG, et al. Physical exercises for breast cancer survivors: effects of 10 weeks of training on upper limb circumferences. J Phys Ther Sci. 2016;28:2778-84.

60. Schmitz KH, Ahmed RL, Troxel AB, Cheville A, Lewis-Grant L, Smith R, et al. Weight lifting for women at risk for breast cancerrelated lymphedema: a randomized trial. JAMA. 2010;304:2699705.

61. Ammitzbøll G, Johansen C, Lanng C, Andersen EW, Kroman N, Zerahn B, et al. Progressive resistance training to prevent arm lymphedema in the first year after breast cancer surgery: results of a randomized controlled trial. Cancer. 2019;125:1683-92.

62. Ferguson CM, Swaroop MN, Horick N, Skolny MN, Miller CL, Jammallo LS, et al. Impact of ipsilateral blood draws, injections, blood pressure measurements, and air travel on the risk of lymphedema for patients treated for breast cancer. J Clin Oncol. 2016;34: 691.

63. Kilbreath SL, Refshauge KM, Beith JM, Ward LC, Ung OA, Dylke ES, et al. Risk factors for lymphoedema in women with breast cancer: a large prospective cohort. Breast. 2016;28:29-36.

64. Yüksel A, Gürbüz O, Velioğu Y, Kumtepe G, Șenol S (2016) Management of lymphoedema

65. Sanal-Toprak C, Ozsoy-Unubol T, Bahar-Ozdemir Y, Akyuz G. The efficacy of intermittent pneumatic compression as a substitute for manual lymphatic drainage in complete decongestive therapy in the treatment of breast cancer related lymphedema. Lymphology. 2019;52:82-91.

66. Ridner SH, Dietrich MS, Deng J, Ettema SL, Murphy B (2021) Advanced pneumatic compression for treatment of lymphedema of the head and neck: a randomized wait-list controlled trial 1-9

67. Zuther JE, Norton S. Lymphedema management: the comprehensive guide for practitioners. New York: Thieme; 2018.

68. Mayanagi S, Ishikawa A, Matsui K, Matsuda S, Irino T, Nakamura R, Fukuda K, Wada N, Kawakubo H, Hijikata N (2020) Association of preoperative sarcopenia with postoperative dysphagia in patients with thoracic esophageal cancer

69. Baguley BJ, Bolam KA, Wright ORL, Skinner TL. The effect of nutrition therapy and exercise on cancer-related fatigue and quality of life in men with prostate cancer: a systematic review. Nutrients. 2017;9:1003. https://doi.org/10.3390/nu9091003.

70. Uster A, Ruehlin M, Mey S, Gisi D, Knols R, Imoberdorf R, et al. Effects of nutrition and physical exercise intervention in palliative cancer patients: a randomized controlled trial. Clin Nutr. 2017;37: 1202-9. https://doi.org/10.1016/j.clnu.2017.05.027.

71. Arends J. Struggling with nutrition in patients with advanced cancer: nutrition and nourishment - focusing on metabolism and supportive care. Ann Oncol. 2018;29:ii27-34.

72. Liang W, Guan W, Chen R, Wang W, Li J, Xu K, et al. Cancer patients in SARS-CoV-2 infection: a nationwide analysis in China. Lancet Oncol. 2020;21:335-7.

73. Mehta V, Goel S, Kabarriti R, Cole D, Goldfinger M, AcunaVillaorduna A, et al. Case fatality rate of cancer patients with COVID-19 in a New York hospital system. Cancer Discov. 2020;10:935-41.

74. Spicer J, Chamberlain C, Papa S. Provision of cancer care during the COVID-19 pandemic. Nat Rev Clin Oncol. 2020;17:329-31.
75. Sell NM, Silver JK, Rando S, Draviam AC, Santa Mina D, Qadan M. Prehabilitation telemedicine in neoadjuvant surgical oncology patients during the novel COVID-19 coronavirus pandemic. Ann Surg. 2020;272:e81-3.

76. Morrison KS, Paterson C, Toohey K. The feasibility of exercise interventions delivered via telehealth for people affected by cancer: a rapid review of the literature. Semin Oncol Nurs. 2020;36: 151092. Review of existing literature on virtual exercise interventions for cancer patients during the COVID-19 pandemic.

77. Lopez CJ, Edwards B, Langelier DM, Chang EK, Chafranskaia A, Jones JM (2021) Delivering virtual cancer rehabilitation programming during the first 90 days of the COVID-19 pandemic: a multimethod study. Arch Phys Med Rehabil

78. Chang PJ, Jay GM, Kalpakjian C, Andrews C, Smith S (2021) Patient and provider-reported satisfaction of cancer rehabilitation telemedicine visits during the COVID-19 pandemic

79. Rao RM, Amritanshu R, Vinutha HT, Vaishnaruby S, Deepashree $\mathrm{S}$, Megha M, et al. Role of yoga in cancer patients: expectations, benefits, and risks: a review. Indian J Palliat Care. 2017;23:22530. https://doi.org/10.4103/IJPC.IJPC_107_17.

80. Hilfiker R, Meichtry A, Eicher M, Nilsson Balfe L, Knols RH, Verra ML, et al. Exercise and other non-pharmaceutical interventions for cancer-related fatigue in patients during or after cancer treatment: a systematic review incorporating an indirectcomparisons meta-analysis. Br J Sports Med. 2018;52:651-8. https://doi.org/10.1136/bjsports-2016-096422.

81. Patel AV, Friedenreich CM, Moore SC, Hayes SC, Silver JK, Campbell KL, et al. American College of Sports Medicine roundtable report on physical activity, sedentary behavior, and cancer prevention and control. Med Sci Sports Exerc. 2019;51:2391402.

82. Cormie P, Zopf EM, Zhang X, Schmitz KH. The impact of exercise on cancer mortality, recurrence, and treatment-related adverse effects. Epidemiol Rev. 2017;39:71-92. https://doi.org/10.1093/ epirev/mxx007.

83.• Stout NL, Baima J, Swisher AK, Winters-Stone K, Welsh J. A systematic review of exercise systematic reviews in the cancer literature (2005-2017). PM R. 2017;9:S347-84. A systematic review on exercise in cancer patients, highlighting the benefits exercise can have at all stages of cancer treatment and across all cancer types.

84.• Schmitz KH, Campbell AM, Stuiver MM, Pinto BM, Schwartz AL, Morris GS, et al. Exercise is medicine in oncology: engaging clinicians to help patients move through cancer. CA Cancer J Clin. 2019;69:468-84. This article provides recommendations and tools for providers to address the underutilization of exercise in cancer patients.

85. Yang DD, Hausien O, Aqeel M, Klonis A, Foster J, Renshaw D, et al. Physical activity levels and barriers to exercise referral among patients with cancer. Patient Educ Couns. 2017;100: 1402-7.

86. Lau CHY, Wu X, Chung VCH, Liu X, Hui EP, Cramer H, et al. Acupuncture and related therapies for symptom management in palliative cancer care: systematic review and meta-analysis. Medicine (Baltimore). 2016;95:e2901. https://doi.org/10.1097/ MD.0000000000002901.

87. Zhang Y, Lin L, Li H, Hu Y, Tian L. Effects of acupuncture on cancer-related fatigue: a meta-analysis. Support Care Cancer. 2018;26:415-25. https://doi.org/10.1007/s00520-017-3955-6.

88. B Behzadmehr R, Dastyar N, Moghadam MP, Abavisani M, Moradi M. Effect of complementary and alternative medicine interventions on cancer related pain among breast cancer patients: a systematic review. Complement Ther Med. 2020;49:102318. A systematic review of complementary and alternative medicine interventions including yoga, tai chi, acupuncture, and meditation for cancer pain in breast cancer patients. 
89. Chiu HY, Hsieh YJ, Tsai PS (2017) Systematic review and metaanalysis of acupuncture to reduce cancer-related pain. Eur J Cancer Care (Engl) 26. https://doi.org/10.1111/ecc.12457

90. Haller H, Winkler MM, Klose P, Dobos G, Kummel S, Cramer H. Mindfulness-based interventions for women with breast cancer: an updated systematic review and meta-analysis. Acta Oncol. 2017;56:1665-76. https://doi.org/10.1080/0284186X.2017. 1342862.

91. Pinheiro da Silva F, Moreira GM, Zomkowski K, Amaral de Noronha M, Flores Sperandio F. Manual therapy as treatment for chronic musculoskeletal pain in female breast cancer survivors: a systematic review and meta-analysis. J Manip Physiol Ther. 2019;42:503-13.

92. Tai JB, Hong L, Ma ME, Xu J, Fang JQ, Jiang YQ. Evaluation of therapeutic effect of transcutaneous electrical acupoint stimulation on bone metastasis pain and its influence on immune function of patients. Ann Palliat Med. 2020;9:2538-44. https://doi.org/10. 21037/apm-19-434.

93. Greenlee H, DuPont-Reyes M, Balneaves LG, Carlson LE, Cohen MR, Deng G, et al. Clinical practice guidelines on the evidencebased use of integrative therapies during and after breast cancer treatment. CA Cancer J Clin. 2017;67:194-232. https://doi.org/10. $3322 /$ caac. 21397.

94. Kramer JL. Medical marijuana for cancer. CA Cancer J Clin. 2015;65:109-22. https://doi.org/10.3322/caac.21260.

95. Miccinilli S, Bravi M, Maselli M, Santacaterina F, Morrone M, Manco D, et al. The effectiveness of extracorporeal shock wave therapy on breast cancer-related lymphedema: a literature review. Lymphology. 2020;53:118-35.

96. Crevenna R, Mickel M, Keilani M. Extracorporeal shock wave therapy in the supportive care and rehabilitation of cancer patients. Support Care Cancer. 2019;27:4039-41. https://doi.org/10.1007/ s00520-019-05046-y.

97. Guo Y, Molinares D. Precautions for yoga practice are necessary in cancer patients. Support Care Cancer. 2020;28:3981-2. https:// doi.org/10.1007/s00520-019-05154-9.

98. Sicard-Rosenbaum L, Danoff JV, Guthrie JA, Eckhaus MA. Effects of energy-matched pulsed and continuous ultrasound on tumor growth in mice. Phys Ther. 1998;78:271-7.

99. Gutin PH, Wong ET. Noninvasive application of alternating electric fields in glioblastoma: a fourth cancer treatment modality. Am Soc Clin Oncol Educ Book. 2012;32:126-31.

100. Kahan M, Srivastava A, Spithoff S, Bromley L. Prescribing smoked cannabis for chronic noncancer pain: preliminary recommendations. Can Fam Physician. 2014;60:1083-90.

101. Sawtelle L, Holle LM (2020) Use of cannabis and cannabinoids in patients with cancer. Ann Pharmacother 1060028020965224. doi: https://doi.org/10.1177/1060028020965224.

102. Zolotov Y, Eshet L, Morag O. Preliminary assessment of medical cannabis consumption by cancer survivors. Complement Ther Med. 2021;56:102592.

103. Hou W, Pei L, Song Y, Wu J, Geng H, Chen L, et al. Acupuncture therapy for breast cancer-related lymphedema: a systematic review and meta-analysis. J Obstet Gynaecol Res. 2019;45:230717. https://doi.org/10.1111/jog.14122.

104. Jin Y, Wang Y, Zhang J, Xiao X, Zhang Q. Efficacy and safety of acupuncture against chemotherapy-induced peripheral neuropathy: a systematic review and meta-analysis. Evid Based Complement Alternat Med. 2020;2020:8875433. https://doi.org/ 10.1155/2020/8875433.

105. Sun L, Mao JJ, Liu Q, Yang Y, He B. Effects of auricular acupuncture on appetite in patients with advanced cancer: a pilot randomized controlled trial. Ann Palliat Med. 2020;9:1804-11. https://doi.org/10.21037/apm.2020.04.24.

106. Van Hal M, Dydyk AM, Green MS (2020) Acupuncture. In: Anonymous StatPearls, StatPearls Publishing LLC, Treasure Island (FL)

107. Wilkinson J, Falerio R. Acupuncture in pain management. Crit Care Pain. 2007:7:135-8.

108. Galantino ML, Brooks J, Tiger R, Jang S, Wilson KA (2020) Effectiveness of yoga and meditation for chemotherapy-induced peripheral neuropathy: a pilot study featuring minority recruitment

109. Mascaro JS, Waller AV, Wright L, Leonard T, Haack C, Waller EK. Individualized, single session yoga therapy to reduce physical and emotional symptoms in hospitalized hematological cancer patients. Integr Cancer Ther. 2019;18:1534735419861692.

110. Lu W, Rosenthal DS. Recent advances in oncology acupuncture and safety considerations in practice. Curr Treat Options in Oncol. 2010;11:141-6. https://doi.org/10.1007/s11864-010-0126-0.

111. Wilairat P, Kengkla K, Kaewpanan T, Kaewthong J, Ruankon S, Subthaweesin C, et al. Comparative efficacy and safety of interventions for preventing chemotherapy-induced oral mucositis in adult cancer patients: a systematic review and network meta-analysis. Eur J Hosp Pharm. 2020;27:103-10. https://doi.org/10.1136/ ejhpharm-2018-001649.

112. Shigematsu H, Hirata T, Nishina M, Yasui D, Ozaki S Cryotherapy for the prevention of weekly paclitaxel-induced peripheral adverse events in breast cancer patients. Support Care Cancer. 2020;28:5005-11. https://doi.org/10.1007/s00520-02005345-9.

113. Anthony J (2018) Report on the use of extracorporeal shockwave therapy in orthopaedic conditions

114. Auersperg V, Trieb K. Extracorporeal shock wave therapy: an update. Efort Open Rev. 2020;5:584-92. https://doi.org/10.1302/ 2058-5241.5.190067.

115. Krisciunas GP, Vakharia A, Lazarus C, Taborda SG, Martino R, Hutcheson K, et al. Application of manual therapy for dysphagia in head and neck cancer patients: a preliminary national survey of treatment trends and adverse events. Glob Adv Health Med. 2019;8:2164956119844151. https://doi.org/10.1177/ 2164956119844151.

116. Allan GM, Finley CR, Ton J, Perry D, Ramji J, Crawford K, et al. Systematic review of systematic reviews for medical cannabinoids: pain, nausea and vomiting, spasticity, and harms. Can Fam Physician. 2018;64:e78-94.

117. Dobkin PL, Irving JA, Amar SA. For whom may participation in a mindfulness-based stress reduction program be contraindicated? Mindfulness. 2012;3:44-50.

118. Anschau F, Webster J, Capra MEZ, de Azeredo da Silva ALF, Stein AT. Efficacy of low-level laser for treatment of cancer oral mucositis: a systematic review and meta-analysis. Lasers Med Sci. 2019;34:1053-62. https://doi.org/10.1007/s10103-019-02722-7.

119. Baxter GD, Liu L, Petrich S, Gisselman AS, Chapple C, Anders JJ, et al. Low level laser therapy (photobiomodulation therapy) for breast cancer-related lymphedema: a systematic review. BMC Cancer. 2017;17:833. https://doi.org/10.1186/s12885-017-3852-x.

120. Nakano J, Ishii K, Fukushima T, Ishii S, Ueno K, Matsuura E, et al. Effects of transcutaneous electrical nerve stimulation on physical symptoms in advanced cancer patients receiving palliative care. Int J Rehabil Res. 2020;43:62-8. https://doi.org/10. 1097/MRR.0000000000000386.

Publisher's Note Springer Nature remains neutral with regard to jurisdictional claims in published maps and institutional affiliations. 